\title{
ASO Author Reflections: Breast Cancer: What is in a Positive Node?
}

\author{
Roi Weiser, MD (1), and V. Suzanne Klimberg, MD, PhD, MHSCT, FACS \\ Department of Surgery, The University of Texas Medical Branch, Galveston, TX
}

\section{PAST}

The prognosis for breast cancer has always relied on nodal staging. ${ }^{1}$ Initially, all tumors received chemotherapy regardless of nodal status. Then TAILORx showed that not all node-negative patients benefited from chemotherapy. ${ }^{2}$ More recently, data presented from the RxPONDER trial has demonstrated that not all node-positive patients benefited from chemotherapy. ${ }^{3}$ So, nodal status alone is not predictive of chemotherapy benefit. However, in terms of prognosis, nodal status in addition to recurrence score (RS) remains important. ${ }^{4}$ The authors wanted to know whether multiple micromets differ from a single micromet in terms of prognostic information and whether single versus multiple micromets respond to chemotherapy differently.

\section{PRESENT}

The current study found that patients with more than one micrometastatic lymph node have worse prognostic characteristics and worse overall survival than those with a single micrometastasis, similar to patients with macrometastatic disease affecting one lymph node. ${ }^{5}$ These findings might motivate clinicians to treat these patients with systemic chemotherapy, but the findings demonstrated

(C) Society of Surgical Oncology 2021

First Received: 25 June 2021

Accepted: 29 June 2021;

Published Online: 13 July 2021

R. Weiser, MD

e-mail: roiweiser@yahoo.com

V. S. Klimberg, MD, PhD, MHSCT, FACS

e-mail: vsklimbe@utmb.edu that the patients with micrometastases to one or more of their lymph nodes and an RS of 25 or lower have only a minimal survival advantage with adjuvant chemotherapy.

\section{FUTURE}

Therefore, the authors advise clinicians to take into consideration these unique prognostic and predictive implications of multiple lymphatic micrometastases during shared decision-making with their patients. These implications should be considered especially for young patients with micromets, who do not fall under either TAILORx or RxPONDER recommendations.

DISCLOSURE There are no conflicts of interest.

\section{REFERENCES}

1. Giuliano AE, Edge SB, Hortobagyi GN. Eighth edition of the AJCC cancer staging manual: breast cancer. Ann Surg Oncol. 2018;25:1783-5. https://doi.org/10.1245/s10434-018-6486-6.

2. Sparano JA, Gray RJ, Makower DF, et al. Prospective validation of a 21-gene expression assay in breast cancer. $N$ Engl J Med. 2015;373:2005-14. https://doi.org/10.1056/NEJMoa1510764.

3. Kalinsky K, Barlow W, Meric-Bernstam F, Garlow J, Albain K. Oral presentation [GS3-00], SWOG S1007: adjuvant trial randomized ER+ patients who had a recurrence score $<25$ and 1-3 positive nodes to endocrine therapy (ET) versus ET + chemotherapy. In: San Antonio Breast Cancer Symposium. 2020.

4. Weiser R, Haque W, Polychronopoulou E, et al. The 21-gene recurrence score in node-positive, hormone receptor-positive, HER2-negative breast cancer: a cautionary tale from an NCDB analysis. Breast Cancer Res Treat. 2020. https://doi.org/10.1007/ s10549-020-05971-1.

5. Weiser R, Polychronopoulou E, Haque W, et al. Prognosis and chemotherapy use in breast cancer patients with multiple lymphatic micrometastases: an NCDB analysis. Ann Surg Oncol. 2021. https://doi.org/10.1245/s10434-021-10374-7.

Publisher's Note Springer Nature remains neutral with regard to jurisdictional claims in published maps and institutional affiliations. 